DOI 10.1590/1807-01912014202252

OPCampinasV20N2

\title{
Desenho institucional e promoção da justiça em espaços participativos: implicações em um estudo de caso
}

\begin{tabular}{c}
\hline \hline Rafael da Silva \\
Departamento de Ciências Sociais \\
Universidade Estadual de Maringá \\
Doutorando em Sociologia Política \\
Universidade Federal de Santa Catarina \\
\hline \hline
\end{tabular}

Resumo: Do conjunto de estudos sobre os impactos do Orçamento Participativo (OP), uma linha de investigação tem apontado seu potencial redistributivo, compreendendo-o como a concretização da equidade e do princípio da diferença, elementos estruturantes da concepção de justiça de John Rawls. Assim, este artigo averigua se esse potencial se concretizou na experiência de OP de Biguaçu-SC. Constata-se, diante do cruzamento dos dados de investimento per capita com o Índice de Vulnerabilidade Social (IVS) por região, que, em partes, a experiência promoveu a justiça, porém, essa promoção esteve limitada pela mudança no desenho institucional da experiência, que impactou diretamente na redução da equidade.

Palavras-chave: redistribuição; justiça como equidade; princípio da diferença; desenho institucional; orçamento participativo

Abstract: Among the studies on the Participatory Budgeting (PB) impacts, a line of research has shown its redistributive potential, comprehending it as the consolidation of equality and the difference principle, framework elements of the conception of justice, by John Rawls. Therefore, this article aimes to verify if this potential was achieved in the PB experience of the city of Biguaçu in Santa Catarina, Brazil. The study proves through cross tabulation of the per capita investiment and the Social Vulnerability Index (SoVI) per region, that, in part, the experience promoted justice. However, this promotion was limited by the changes in the institutional design of the experience, which caused a direct impact on the equality reduction.

Keywords: redistribution; justice as fairness; difference principle; institutional design; participatory budgeting

OPINIÃO PÚBLICA, Campinas, vol. 20, no 2, agosto, 2014, p. 252-272 
SILVA, R. Desenho institucional e promoção da justiça em espaços participativos:... Introdução ${ }^{1}$

As condições socioeconômicas vividas pelos brasileiros são de suma importância para a consolidação e ampliação da democracia restaurada no final da década de 1980 . Por um lado, o contexto em que os cidadãos estão insertos incide em seu engajamento ${ }^{2}$ nas questões políticas: as de caráter geral, acerca de temáticas nacionais, e as de caráter local, acerca das condições vividas nos bairros e nos municípios onde residem. Por outro, também impõe um enorme desafio a esta jovem democracia e às autoridades públicas que habitam suas instituições, demandando que se produzam outputs adequados às suas demandas que, a médio e longo prazo, impactem em suas condições de vida, melhorando seu bem-estar e revertendo o status quo em vigor. Macpherson (1978) e Pateman (1992) apontam que esse desafio é uma conditio sine qua non para que os regimes democráticos se consolidem e ampliem.

A realidade brasileira, de um país periférico ${ }^{3}$, é marcada pela existência de um padrão de desigualdade estrutural que oferece entraves à democracia. Conforme apontamentos de Souza (2003a; 2003b; 2006), consolidou-se historicamente um exército de "não gente", de indivíduos proibidos de usufruírem das benesses da cooperação social em uma sociedade de capitalismo moderno. Esse quadro, ao invés de ser resolvido, foi alargado no processo de construção do país, legando contingente populacional cada vez mais crescente à condição de subcidadania. Cristalizando, com isso, um ciclo vicioso que afeta diretamente a saúde do regime político, já que "as desigualdades promovem a apatia do eleitorado de um lado, a apatia impede uma participação no sentido de diminuir as desigualdades de outro" (MIGUeL, 2005, p. 27).

Assim, o grande desafio posto diz respeito a como quebrar esse ciclo, permitindo que, gradativamente, dirimam-se as discrepâncias socioeconômicas, produzindo condições de acesso a bens e serviços públicos mais equitativos. De alguma forma, esse desafio tem sido assumido através de diversas frentes, e uma delas vem apresentando bons resultados: as experiências de Orçamento Participativo (OP). Os OPs são espaços participativos/deliberativos onde a população decide o destino de parte dos recursos públicos que o governo municipal estima aplicar no município via orçamento público municipal. Logo, altera-se o modelo tradicional, onde a construção, discussão, aprovação, implementação e fiscalização do orçamento público municipal são monopolizados pelos ocupantes dos cargos eletivos municipais: o prefeito, que possui a prerrogativa de elaborar o orçamento, os vereadores, aos quais cabe a aprovação e fiscalização, e, à população em geral, cabe elegê-los. Agora, com o OP, a população participa da discussão e definição quanto à aplicação de parte desse orçamento, que é canalizado pelo executivo municipal para as instâncias decisórias do OP, para que elas atribuam empenho e destino aos recursos.

\footnotetext{
${ }^{1} \mathrm{O}$ autor agradece às diversas pessoas que contribuíram com o artigo: Julian Borba (UFSC), Roberto Rocha Pires (IPEA), Erni Seibel (UFSC), Lígia Lüchmann (UFSC), a equipe do Núcleo de Pesquisa em Participação Política da Universidade Estadual de Maringá - NUPPOL/UEM (professores: Carla Almeida, Celene Tonela, Ednaldo Aparecido Ribeiro e José Antônio), Patrícia Alves da Cruz (UNIVALE) e os pareceristas anônimos da Revista Opinião Pública.

2 Estudos apontam a renda e escolaridade como preditores da participação política dos cidadãos, resultando em uma elitização da participação por um lado, onde participam os mais escolarizados e de melhor renda, e por outro, uma apatia generalizada da população mais pobre (SARTORI, 1994; MIGUEL, 2005).

${ }^{3}$ Segundo Souza (2003a), países periféricos são aqueles cujo processo de modernização ocorreu de forma tardia se comparado à realidade dos países centrais da Europa, e que, por consequência direta, possibilitou a apenas uma parte da população a integração a esta nova sociedade, capitalista moderna e competitiva. Esse processo modernizador de caráter seletivo legou a uma grande parcela da população o esquecimento e a subcidadania. Assim, a desigualdade nos países de modernização tardia assume característica de um fenômeno de massa, de ordem estrutural, enquanto nos países mais centrais é apenas um fenômeno circunstancial.
} 


\section{OPINIÃO PÚBLICA, Campinas, vol. 20, no 2, agosto, 2014, p. $252-272$}

Assim, através de mecanismos que articulam participação direta na base e representação, o OP possibilita uma capilaridade maior no processo de tomada de decisão, incluindo um grande contingente populacional no processo, que antes era concentrado no executivo e legislativo municipal. Desde a sua primeira aparição, em 1989, na gestão de Olívio Dutra (PT) na Prefeitura Municipal de Porto Alegre (RS), o OP proliferou em número de experiências, dentro e fora do Brasil ${ }^{4}$, e de estudos que focaram alguns de seus aspectos e impactos ${ }^{5}$. Uma dessas abordagens tem apontado o OP como uma experiência produtora de efeitos redistributivos dos gastos públicos municipais.

Ou seja, diante de um padrão de aplicação dos recursos públicos, o qual foi consolidado historicamente e priorizou regiões mais nobres e centrais das cidades na destinação de bens e serviços públicos, o OP surge como prática reversora dessa lógica distributiva. Com a entrada dessa experiência em vigor, regiões que outrora eram negligenciadas, principalmente as mais carentes, periféricas, de maior ausência do poder público, tornaram-se prioridades nos investimentos dos recursos públicos via OP. É nesse aspecto que há um efeito redistributivo, mudando-se a lógica de distribuição vigente, canalizando, a partir de agora, montante maior de recursos para investimentos prioritários nas áreas menos "nobres" e "centrais" da cidade, em detrimento de outras menos necessitadas.

Dois estudos pioneiros identificam essa característica no OP (MARQUETTI, 2003; AVRITZER; PIRES, 2005) ${ }^{6}$. Os autores advogam, a partir do estudo de três experiências (Porto Alegre, Belo Horizonte e São Paulo), que as decisões de investimentos no interior do OP priorizaram regiões mais carentes, contrapondo-se à lógica distributiva vigente até antes da entrada em vigor da experiência. Assim, na montagem da peça orçamentária do ano seguinte, o executivo destina um determinado percentual de recursos extraídos do orçamento geral, para que as instâncias decisórias do OP definam o destino dos recursos. Em geral, o ciclo do OP contempla um conjunto de espaços participativos e deliberativos, assembleias regionais ${ }^{7}$ e comunitárias, fórum regional, fóruns temáticos e plenárias temáticas (por temas de investimento), de onde saem as prioridades de investimentos, definida por cada região através de um processo de mobilização e discussão entre os seus moradores. Essas demandas são dirigidas em geral ao Conselho do Orçamento Participativo (COP), instância formada por representantes de cada região e comunidade, os delegados e conselheiros, que montam a peça orçamentária do OP, dando destino aos recursos, além de fiscalizar a aplicação dos mesmos ao longo do ano. Essa peça é enviada ao executivo que remete ao legislativo, voltando posteriormente ao executivo para a sanção, conforme os trâmites normais entre os poderes constituídos do Estado.

Segundo Lüchmann (2002), para o caso da experiência porto-alegrense, coletadas as demandas prioritárias, aplicava-se um conjunto de critérios para definir o montante a ser aplicado em cada região, levando em consideração: a mobilização popular da região, a carência da população em infraestrutura e serviços e população em área de carência máxima. Assim, esses critérios definiriam cinco regiões prioritárias que receberiam $70 \%$ dos recursos do OP, os outros $30 \%$ eram partilhados entre as outras regiões menos prioritárias. Desta forma, apesar de existirem outros fatores que contribuíram

\footnotetext{
4 A gestão municipal encerrada em 2004, quinze anos depois da experiência pioneira, contabilizou 194 municípios com OP, segundo o Projeto Democracia Participativa, conforme Avritzer e Pires (2005).

${ }_{5}^{5}$ Para mais detalhes, ver Andrade e Moura (2000).

${ }^{6}$ É importante citar outros estudos desenvolvidos posteriormente: Carlos (2007) estuda as experiências dos municípios de Vitória e de Serra, dedicando um capítulo para o estudo do efeito redistributivo e o livro organizado por Marquetti, Campos e Pires (2008) que estuda, sob a ótica redistributiva, várias experiências de OP.

7 município era dividido em diversas regiões que apresentariam suas demandas.
} 
SILVA, R. Desenho institucional e promoção da justiça em espaços participativos:...

decisivamente para a virtuosidade da experiência, como o comprometimento do governo com o OP e a tradição associativa do município ${ }^{8}$, o desenho institucional aparece como o fator que atuou mais diretamente na mudança da lógica distributiva vigente.

Quando se fala em desenho institucional, refere-se basicamente a um "conjunto de regras, critérios, espaços, normas, leis, que visam fazer valer e promover a realização prática dos princípios democrático-participativos" (LÜCHMANN, 2002, p. 143). Formalizando o processo decisório, moldando comportamentos, escolhas, além de dar durabilidade ao processo, não o tornando refém de interesses políticos mais efêmeros, e conferindo caráter público às escolhas.

É nessa perspectiva que assenta este artigo, propondo-se averiguar se: 1) o OP do município de Biguaçu, localizado na região da Grande Florianópolis onde se localiza a capital do estado de Santa Catarina, promoveu o potencial redistributivo constatado em outras experiências e como 2) o desenho institucional atuou nesse contexto, no que tange o potencial redistributivo. Para alcançar os objetivos estabelecidos, esse artigo possui a seguinte estrutura: além dessa introdução, há uma segunda parte dedicada a uma breve apresentação do OP de Biguaçu, outra destinada à metodologia, explanando os procedimentos adotados no tratamento dos dados, na quarta parte apresenta-se o aporte teórico que sustenta a concepção de justiça adotada, na quinta, as análises dos dados e, por fim, as considerações finais.

\section{O OP de Biguaçu-SC}

O OP no município iniciou em 2001 como cumprimento de uma promessa de campanha da coligação "Compromisso com o Povo" (PMDB e PT) ${ }^{9}$, que saiu vitoriosa do pleito municipal ocorrido no ano anterior, 2000. Segundo Nobre,

“[...] o processo de formação, discussão e elaboração do OP em Biguaçu foi mais diretamente vinculado a um plano de governo do que resultado da participação dos setores organizados da sociedade civil local, que estiveram de fora das discussões iniciais do OP" (NOBRE, 2007, p. 115).

Sendo o OP uma bandeira histórica do PT, coube ao partido a responsabilidade, em grande medida, de iniciar o processo de construção da experiência. Ela começou com uma equipe executiva formada por três membros, dois do PT, inclusive a coordenadora, e mais um membro do PMDB. O OP do município de Chapecó e Porto Alegre foram as vitrines que moldaram a experiência de Biguaçu, inclusive no tocante ao desenho institucional. Assim, O OP surgiu alicerçado em uma engenharia institucional que envolvia assembleias comunitárias (total de 35), assembleias regionais (total de 10, equivalente ao número de regiões), plenárias temáticas (educação, saúde, habitação etc.), o Conselho do Orçamento Participativo (COP) e, por fim, um conjunto de pesos que eram responsáveis pela determinação do percentual de investimentos que uma região receberia, priorizando, como na capital gaúcha, as regiões mais desassistidas.

Conforme Nobre (2007), o ciclo do OP se iniciava com as assembleias comunitárias e regionais, o fórum de delegados e a montagem parcial do Conselho do Orçamento Participativo (COP). Das

\footnotetext{
8 Para mais detalhes, ver Lüchmann (2002) e Avritzer (2003).

${ }^{9}$ Do PMDB, saiu o candidato a prefeito e, do PT, o candidato a vice-prefeito.
} 


\section{OPINIÃO PÚBLICA, Campinas, vol. 20, no 2, agosto, 2014, p. $252-272$}

assembleias saiam os delegados e conselheiros regionais eleitos para formar o COP, bem como as prioridades de investimentos, essas prioridades eram submetidas a um conjunto de critérios: população (peso 2), carência de serviços públicos (peso 3) e prioridade escolhida pela população (peso 4). Com isso, chegava-se a uma nota que servia de base para estipular o percentual de investimento destinado a cada região, fechando assim a primeira etapa.

$\mathrm{Na}$ segunda etapa, ocorriam as plenárias temáticas para discutir temas específicos e o orçamento municipal geral voltado para os seguintes temas: pavimentação, saúde, educação, esporte, cultura, lazer, assistência social dentre outros. Nessas plenárias era eleita a segunda leva de delegados, os delegados temáticos, que integrariam o COP, junto aos já eleitos na etapa anterior. No segundo semestre a nova formação do COP iniciava suas atividades de fiscalização, propositura e deliberação sobre assuntos referentes ao orçamento municipal.

Desde seu limiar, o OP foi marcado por conflitos internos à base do governo, principalmente no que diz respeito ao desenho assumido pela experiência, além da resistência de setores do PMDB municipal. Como o OP é uma marca histórica do "jeito petista" de governar, os membros da coordenação da experiência ligados ao PT, principalmente a coordenadora, defendiam o atual formato, e isso gerou conflitos já no processo de implantação. Como os desentendimentos não foram sanados, além de se acumularem ao longo do tempo, o PT rompeu com a administração municipal e se retirou do OP, deixando a experiência sob total comando do PMDB. Após esse rompimento, o OP sofreu consideráveis alterações em seu desenho institucional que se materializaram em um novo regimento interno aprovado no ano de 2005 e implantado no ano seguinte:

1. Eliminação das 35 assembleias comunitárias, diminuindo os espaços participativo. deliberativos;

II. Por consequência, alteração na escolha dos delegados que agora são escolhidos somente nas assembleias regionais junto com os conselheiros;

III. Conservação da proporção de um delegado para cada 10 participantes das assembleias, com a garantia de no mínimo um representante, mesmo que o quórum seja inferior a 10 participantes em alguma região;

IV. Extinção dos critérios de pontuação que pontuava as necessidades das regiões segundo a carência, população e prioridades definidas em assembleias, comunitárias e regionais;

V. Envio de propostas do secretariado municipal para a apreciação do COP, trazendo maior verticalidade ao processo;

VI. Criação de mais três regiões, totalizando agora 13;

VII. Eliminação das cadeiras cativas da UAMBB e do SINTRASMUB ${ }^{10}$.

Essas mudanças foram feitas sob o pretexto de facilitar a assimilação do processo por parte da população e avaliou-se como resultado, por parte da nova coordenação do OP, a geração de maior eficiência no cumprimento do plano de investimento anual, que, segundo a prestação de contas, atingiram níveis de $97 \%$ nos últimos anos analisados. Como o PMDB passou a ser o único condutor da experiência, o OP tornou-se prioridade para o executivo e seu partido, não só o prefeito como grande

\footnotetext{
10 Associação de moradores de Biguaçu e sindicato dos trabalhadores municipais, respectivamente.
} 
SILVA, R. Desenho institucional e promoção da justiça em espaços participativos:...

parte do seu secretariado ${ }^{11}$ se faziam presentes nas assembleias regionais e nas reuniões do COP. Outro indício de comprometimento do governo local está no aumento dos recursos destinados ao OP. Em 2002, o OP contou com 2,8 milhões de reais para investimentos. Em 2007, esse valor subiu para 5,5 milhões de reais (aumento de $96,4 \%$ ) $^{12}$, segundo os dados disponibilizados pela Secretaria do OP' ${ }^{13}$.

Diante das alterações nas "regras do jogo" no curso da experiência, e sabendo da importância delas na produção dos resultados políticos, as análises referentes ao potencial distributivo do OP serão realizadas considerando os dois momentos separadamente. Dessa forma, com o intuito de identificá-los, eles foram chamados de $1^{\circ}$ momento (2002 - 2005), sob a vigência das antigas regras desde a fundação, e $2^{\circ}$ momento (2006 - 2008), já sob a égide do novo Regimento Interno, pós-rompimento do PT.

\section{Metodologia}

Antes de passar aos resultados, é necessária uma explanação dos procedimentos metodológicos utilizados para sistematizar e preparar os dados para análise. Para avaliar o potencial distributivo do OP, foi necessário construir uma medida que traduza de alguma forma o nível de carência da população de cada região do OP. A medida adotada foi o Índice de Vulnerabilidade Social (IVS), resultado de estudos de outras metodologias de IVS utilizadas em alguns municípios brasileiros ${ }^{14}$. A opção por esse índice se deu pelo fato de se constituir em um índice sintético, que possibilita resumir diversas características socioeconômicas de uma localidade em um valor numérico que varia de 0 a 1 , em que quanto mais próximo de 1 , mais vulnerável é uma região e, quanto mais próximo de zero, menos vulnerável.

Os dados necessários para montar o IVS foram retirados do Censo Demográfico de 2000 do IBGE (Instituto Brasileiro de Geografia e Estatística) ${ }^{15}$, que conta com dados por setor censitário ${ }^{16}$. Como o IBGE oferta as variáveis com algum nível de agregação, o universo de onde foram extraídas as quinze variáveis que compõem o IVS (Tabela 1 ) é de 3.216 variáveis.

\footnotetext{
11 O prefeito convocava os representantes das diversas pastas a estarem presentes nas assembleias regionais e nas reuniões do COP, onde os mesmos prestavam contas do andamento das obras que eram de incumbência de sua secretaria.

$12 \mathrm{Em}$ termos percentuais, em relação ao montante total de recursos do município, o valor saiu da casa dos $2 \%$ e foi para a casa dos $5 \%$ no último ano.

$13 \mathrm{O}$ ponto de interrogação que surge é se a eficiência no cumprimento do plano anual de investimentos e o aumento dos recursos destinados ao OP foram resultados da mudança no desenho da experiência, ou esta ocorrência se deve ao fato de agora ser o PMDB o único a responder pelo sucesso ou fracasso do OP.

14 Para mais informações, seguem as referências dos estudos que inspiraram a construção deste IVS: IVS para a cidade de Belo Horizonte in: NAHAS, OliveIRA e Neto, Portal PUC Minas - APIMEC e IVS para Porto Alegre, Prefeitura de Porto Alegre (2007).

15 O censo é uma pesquisa decenal que abrange todo o território brasileiro, onde são extraídas diversas informações da população brasileira. O de 2000 produziu 527 variáveis que caracterizam os domicílios, os responsáveis e seus residentes.

16 "Os setores têm limites físicos identificáveis em campo que respeitam os limites da divisão político-administrativa, do quadro urbano e rural legal e de outras estruturas territoriais de interesse, além de um quantitativo de domicílios adequado a operação censitária" (IBGE, 2003, p. 4). Os setores censitários, para o ano de 2000, são em número de 215.811 e esgotam todo o território brasileiro. Na média, cada setor possui 230 domicílios e 700 habitantes, sendo este o critério de demarcação dos setores. No caso do município de Biguaçu, a demarcação, com base nesse critério, resultou em 49 setores, expressando a totalidade da municipalidade.
} 
OPINIÃO PÚBLICA, Campinas, vol. 20, no 2, agosto, 2014, p. 252-272

Tabela 1

Síntese das variáveis constitutivas do IVS

\begin{tabular}{|c|c|c|}
\hline Dimensões & Descrição da Variável Física (IBGE) & $\begin{array}{l}\text { Variável } \\
\text { no IBGE }\end{array}$ \\
\hline \multirow[t]{6}{*}{ Domiciliar } & $\begin{array}{l}\text { Domicílios particulares permanentes com outra forma de abastecimento } \\
\text { de água, não canalizada }\end{array}$ & V0028 \\
\hline & Domicílios particulares permanentes sem banheiro, nem sanitário & V0036 \\
\hline & Domicílios particulares improvisados & V0004 \\
\hline & Pessoas com 0 a 4 anos de idade & V1448 \\
\hline & Pessoas com 5 a 9 anos de idade & V1449 \\
\hline & Pessoas com 10 a 14 anos de idade & V1450 \\
\hline \multirow[t]{5}{*}{ Escolaridade } & $\begin{array}{l}\text { Responsáveis por domicílios particulares permanentes sem instrução ou } \\
\text { com menos de } 1 \text { ano de estudo }\end{array}$ & V0580 \\
\hline & $\begin{array}{l}\text { Responsáveis por domicílios particulares permanentes com } 1 \text { ano de } \\
\text { estudo }\end{array}$ & V0581 \\
\hline & $\begin{array}{l}\text { Responsáveis por domicílios particulares permanentes } \\
\text { com } 2 \text { anos de estudo }\end{array}$ & V0582 \\
\hline & $\begin{array}{l}\text { Responsáveis por domicílios particulares permanentes } \\
\text { com } 3 \text { anos de estudo }\end{array}$ & V0583 \\
\hline & $\begin{array}{l}\text { Mulheres responsáveis por domicílios particulares permanentes } \\
\text { sem instrução ou com menos de } 1 \text { ano de estudo }\end{array}$ & V1286 \\
\hline \multirow[t]{4}{*}{ Econômico } & $\begin{array}{l}\text { Responsáveis por domicílios particulares permanentes sem } \\
\text { rendimento nominal mensal }\end{array}$ & V0611 \\
\hline & $\begin{array}{l}\text { Responsáveis por domicílios particulares permanentes com } \\
\text { rendimento nominal mensal de até } 1 / 2 \text { salário mínimo }\end{array}$ & V0602 \\
\hline & $\begin{array}{l}\text { Responsáveis por domicílios particulares permanentes com } \\
\text { rendimento nominal mensal de mais de } 1 / 2 \text { a } 1 \text { salário mínimo }\end{array}$ & V0603 \\
\hline & $\begin{array}{l}\text { Responsáveis por domicílios particulares permanentes com } \\
\text { rendimento nominal mensal de mais de } 1 \text { a } 2 \text { salários mínimos }\end{array}$ & V0604 \\
\hline
\end{tabular}

Fonte: IBGE, Censo 2000, elaboração do autor.

Após extrair as quinze variáveis que compõem o IVS, montou-se um banco de dados no programa Excel, distribuindo-as entre os 49 setores censitários do município, para, em seguida, processar as operações matemáticas até obter o IVS setorizado e o geral. Como as regiões do OP são formadas por vários setores censitários, juntaram-se os setores pertencentes às mesmas regiões ${ }^{17}$, somando os valores de cada variável, possibilitando chegar ao número de 10 regiões para o $1^{\circ}$ momento do OP e 13 para o segundo:

Região 1 - composta pelos setores censitários $A, B, C, D$ e E

Cálculo: I i $A+1$ i $B+\mid$ i $C+\mid$ i $D+\mid$ i $E$ onde:

I i A = Domicílios particulares improvisados no setor censitário A

I i $B=$ Domicílios particulares improvisados no setor censitário $B$

I i $C$ = Domicílios particulares improvisados no setor censitário $C$

I i $D=$ Domicílios particulares improvisados no setor censitário $D$

I i E = Domicílios particulares improvisados no setor censitário E

Somados os valores das variáveis dos setores censitários que compõem cada região, elas foram normalizadas em uma proporção por mil habitantes (1000/h), transformando em um indicador que

\footnotetext{
17 É importante ressaltar que, pelo fato de as regiões do OP não necessariamente obedecerem às divisões dos setores censitários, os dados aglutinados por região possuem uma margem de erro não estimada, mas que em nenhum momento compromete a qualidade e confiabilidade das análises.
} 
SILVA, R. Desenho institucional e promoção da justiça em espaços participativos:...

permite comparar contextos populacionais de diferentes tamanhos e, posteriormente, transformá-los em um índice sintético.

Domicílios particulares improvisados $\times 1000=$ valor "y" \%o (por mil habitantes).

$N^{\circ}$ total de domicílios particulares

Na sequência, transformaram-se os valores por mil obtidos em outros indicadores cujos valores estão compreendidos no intervalo de 0 a 1 , para que depois possa ser iniciado o processo de síntese do índice.

$$
\frac{(V s c-V \min )}{\left(V \max -V_{\min }\right)} \text { onde: }
$$

Vsc: valor do indicador na região $X$

Vmin: valor mínimo da série (de todas as regiões)

Vmax: valor máximo da série (de todas as regiões)

Logo em seguida, os valores das variáveis foram submetidos às operações de somatória, obtendo como produto três índices sintéticos com valores de 0 a 1 (Domiciliar, Escolaridade e Econômico) que resultaram no IVS. Geral, que é uma síntese das quinze características da população utilizadas na construção do índice, onde quanto mais próximo de 1 , mais vulnerável é uma realidade e, quanto mais próximo do zero, menor é a vulnerabilidade.

O passo seguinte à obtenção dos valores dos IVSs (Setorizado e Geral) por região foi classificá-los em cinco categorias, conforme os valores da Figura 1:

Figura 1

\begin{tabular}{|c|c|}
\hline $\begin{array}{c}\text { Extrema } \\
\text { Vulnerabilidade }\end{array}$ & \\
\hline $\begin{array}{c}\text { Alta } \\
\text { Vulnerabilidade }\end{array}$ & $\begin{array}{l}>0,5 \\
\text { até } 0,63\end{array}$ \\
\hline $\begin{array}{c}\text { Relativa } \\
\text { Vulnerabilidade }\end{array}$ & $\begin{array}{l}>0,4 \\
\text { até } 0,5\end{array}$ \\
\hline $\begin{array}{c}\text { Baixa } \\
\text { Vulnerabilidade }\end{array}$ & $\begin{array}{l}>0,28 \\
\text { até } 0.4\end{array}$ \\
\hline $\begin{array}{c}\text { Não } \\
\text { Vulnerável }\end{array}$ & Até 0,28 \\
\hline
\end{tabular}

Classificação do IVS

Fonte: NAHAS; OLIVEIRA; Neto. In: Portal PUC Minas-APIMEC, construção gráfica do autor. 
Para finalizar, após ter obtido o IVS geral, o mesmo foi georreferenciado para que facilitasse a observação do fenômeno, conforme as Figuras 2 e 3 :

Figura 2

IVS Geral segundo as regiões do OP no primeiro momento (2002 - 2005)

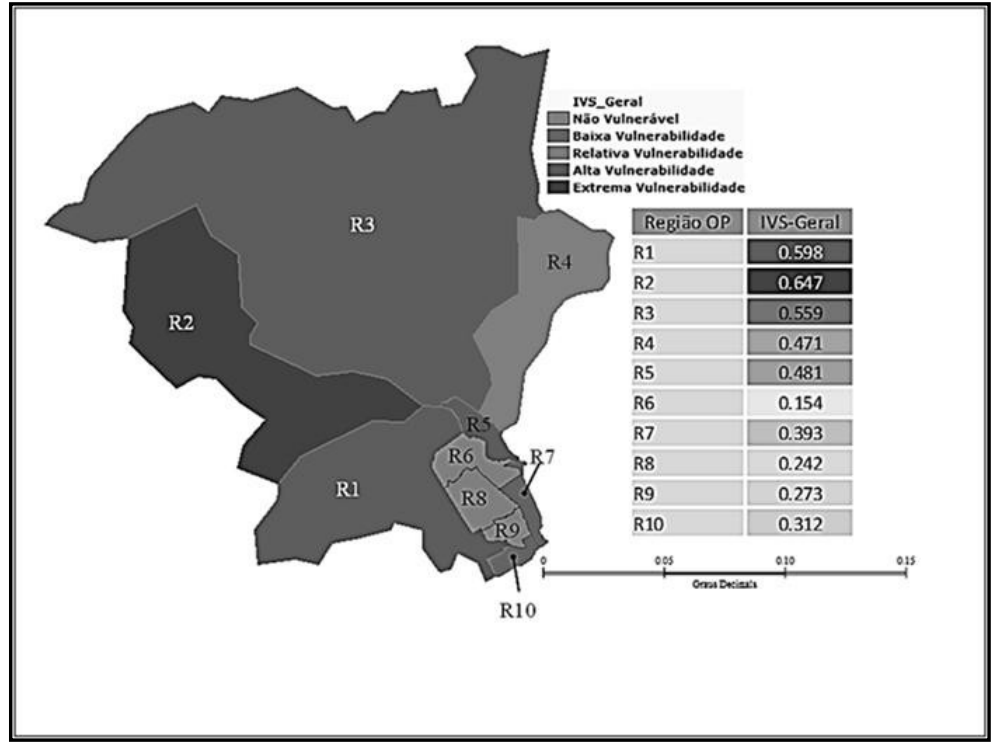

Fonte: IBGE, censo 2000, processamento dos dados feito pelo autor.

Figura 3

IVS Geral segundo as regiões do OP no segundo momento (2006 - 2008)

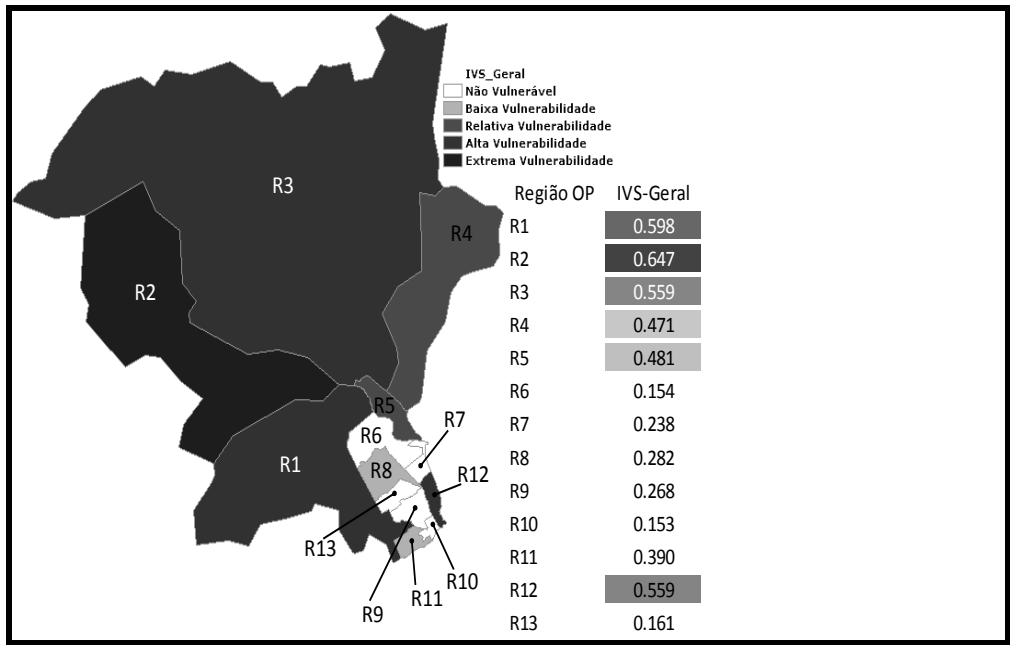

Fonte: IBGE, censo 2000, processamento dos dados feito pelo autor. 
SILVA, R. Desenho institucional e promoção da justiça em espaços participativos:...

É possível constatar que nos dois momentos, as regiões menos vulneráveis são as que ficam próximas à BR 101, principal via de ligação entre o norte e sul do Brasil, e próximas à sede administrativa do município, são elas: no $1^{\circ}$ momento, as regiões $6,7,8$ e 9, e no $2^{\circ}$ momento, as regiões $6,7,8$ e 13. Segundo Koga, "é no território que as desigualdades sociais tornam-se evidentes entre os cidadãos, as condições de vida entre moradores de uma mesma cidade mostram-se diferenciadas, a presença/ausência dos serviços públicos se faz sentir e a qualidade desses mesmos serviços apresentam-se desiguais" (KoGA, 2003, p.33).

Em prefácio à referida obra, Aldaíza Sposati afirma que "sobre a topografia da natureza, erguese uma topografia social. Para além da fluidez das relações, ela incorpora a concretude de condições e acesso como dois elementos imbricados e mutuamente dependentes" (SPOSATI apud KoGA, 2003, p.16). Destarte, afirma-se uma característica das cidades modernas, principalmente nos países periféricos: supervalorização das regiões centrais, e um esquecimento das regiões periféricas. Koga (2003) resgata a história de grandes centros urbanos, principalmente Rio de Janeiro e São Paulo e mostra como os governos locais, apoiado pelas elites, imprimiram políticas higienistas que visaram varrer qualquer vestígio de pobreza das regiões centrais das cidades. No Rio, por exemplo, são emblemáticas as demolições dos cortiços, assim como em São Paulo é a expulsão dos moradores de rua.

\section{Concepção de justiça}

A identificação de um potencial redistributivo em um arranjo democrático confirma a tese de que o OP é uma "inovação democrática"18 gestada e executada em diversos municípios brasileiros, tornando-se produto de exportação. Dos vários aspectos inovadores, foi ressaltado o efeito redistributivo, na medida em que ele é visto como sinônimo de justiça. Portanto, o OP seria uma experiência de participação democrática promotora de justiça. A questão que emerge dessa afirmação refere-se à concepção de justiça que a sustenta.

A concepção assumida baseia-se na teoria da justiça de John Rawls, na medida em que o desenho institucional da experiência, principalmente a gaúcha que é tida como paradigmática, promove a desigualdade entre as regiões do OP, para favorecer as mais desfavorecidas, as mais carentes da ação pública da prefeitura. Para que essa concepção fique mais clara, se faz necessária uma breve explanação da teoria rawlsiana da justiça para identificar o ponto de conexão entre suas reflexões teóricas e a experiência propriamente dita ${ }^{19}$.

A grande empresa do autor foi propor uma concepção de justiça para as sociedades democráticas contemporâneas. O caminho utilizado foi o contrato social sob novas circunstâncias do que aquelas do contratualismo moderno, da tradição liberal clássica. Como afirmou Araújo (2002), a preocupação do liberalismo clássico estava relacionada aos limites do poder, do seu exercício, resultando em uma teoria normativa do governo legítimo que focava no processo de construção de um governo via consentimento voluntário dos seus cidadãos. Já o liberalismo de Rawls, ou como ele mesmo chama de "novo liberalismo" (ARAúso, 2002, p. 77), não baseia suas preocupações na legitimidade, portanto no processo, mas sim no resultado produzido, pois um governo pode ser legítimo sem que seja

\footnotetext{
18 Termo apropriado do livro organizado por Avritzer e Navarro (2003).

19 Assumem-se os riscos inerentes à tentativa de buscar, em uma teoria normativa, subsídios teóricos para a compreensão dos resultados produzidos por uma experiência participativa.
} 


\section{OPINIÃO PÚBLICA, Campinas, vol. 20, no 2, agosto, 2014, p. $252-272$}

justo, e o fato de não ser justo, a médio e longo prazo, compromete sua legitimidade. Tem-se assim, uma concepção de justiça menos procedimental e mais substantiva, preocupada com a moralidade dos resultados produzidos.

Dessa forma, Rawls se enquadra como um pensador liberal, fato que nada diz, caso não esteja clara a pluralidade de discursos tidos como liberais, desde constructos teóricos, ideologias e correntes políticas e partidárias. Portanto, enquadrá-lo assim não é identificar o autor como defensor de um liberalismo econômico de mercado; Rawls "bebe" sim, da vertente política iniciada principalmente com Locke, extrapolando-a. Conforme Chantal Mouffe, conclusão como essa é "resultado da confusão em torno do termo liberalismo, usado numa série de discursos diferentes que, em determinadas circunstâncias, foram articulados em conjunto, mas que não estão necessariamente relacionados" (MouffE, 1996, p. 60). Para a autora, caso queira compreender a modernidade política é necessário

"[...] distinguir duas tradições: liberalismo e democracia, que só foram articuladas no século XIX. E em seguida, é preciso não confundir esta «modernidade política» com o processo de modernização levado a cabo sob o domínio das relações de produção capitalista. [...] Finalmente, há uma série de discursos filosóficos respeitantes à ideia de homem, os critérios de racionalidade, a natureza da moral, etc.; são, por sua vez designados como «filosofia do liberalismo», mas são extremamente heterogêneos [...]" (Mouffe, 1996, p. 61).

Assim,

"a aceitação do liberalismo político não exige que apoiemos igualmente nem o individualismo nem o liberalismo econômico, nem tão pouco nos condena a defesa do universalismo e do racionalismo" (MoufFe, 1996, p. 61).

Seguindo na linha de Mouffe, há, por outro lado, autores que se propuseram a pensar a sociedade democrática e a questão da desigualdade ou promoção da justiça sob a ótica do liberalismo político, destacando-se entre esses o filósofo americano John Rawls. A sua grande contribuição foi elaborar uma "concepção política de justiça para o caso especial da estrutura básica de uma sociedade democrática contemporânea" (RAWLS, 2003, p.19). Essa estrutura é a forma como as diversas instituições interagem em "um sistema de cooperação social, e a maneira como distribuem direitos e deveres básicos e determinam a divisão das vantagens provenientes da cooperação social no transcurso do tempo [...]" (RAWLS, 2003, p. 13).

Como coloca o autor em sua obra O liberalismo político (RAwLS, 2000), a ideia fundante é a de uma sociedade em que vigore um sistema equitativo de cooperação, que não apenas garanta a legitimidade do processo, preservando o esquema de liberdades básicas de forma igual, mas também garanta uma igualdade equitativa, onde a desigualdade somente é aceita se beneficiar os menos favorecidos, o princípio da diferença. Como o próprio autor afirmou, não é uma noção de fácil compreensão e nem muito clara, mas a função da igualdade equitativa é a de "corrigir os defeitos da igualdade formal de oportunidades" (RAWLS, 2002, p.61). Ou seja, cabe à comunidade política, compreendida como um sistema cooperativo, trabalhar em prol do grande empreendimento que é a 
SILVA, R. Desenho institucional e promoção da justiça em espaços participativos:...

constituição de princípios de justiça distributiva, e que os governos os observem no processo de administração do resultado da cooperação.

A justiça como equidade tem como objetivo combinar dois elementos até então imiscíveis: garantias das liberdades e igualdade formal com a busca da redução das desigualdades via princípio de equidade ${ }^{20}$. Assim, a justiça se expressaria na promoção de dois princípios básicos ${ }^{21}$ :

“a) cada pessoa tem o mesmo direito irrevogável a um esquema plenamente adequado de liberdades básicas iguais que seja compatível com o mesmo esquema de liberdade para todos;" e

"b) as desigualdades sociais e econômicas devem satisfazer duas condições: primeiro, devem estar vinculadas a cargos e posições acessíveis a todos em condições de igualdade equitativa de oportunidades; e, em segundo lugar, têm de beneficiar ao máximo os membros menos favorecidos da sociedade (o princípio de diferença)" (RAWLS, 2003, p.60).

Como bem lembrou Araújo (2002), para Rawls é fundamental que uma concepção de justiça trate de questões centrais como a antítese igualdade/desigualdade, apontando aquilo que é moralmente justificável e injustificável como resultado do processo político. Além de mostrar que validar princípios de igualdade em uma dimensão, a formal, não implica em uma universalização dessa igualdade, caso ocorra, a produção de iniquidades se tornará o modus operandi da cooperação social. Mesmo que a equidade seja a base articuladora da justiça, os tradicionais valores individuais e a igualdade formal são centrais, o que implica afirmar que a justiça como equidade "baseia-se em valores políticos e não deveria ser apresentada como parte de uma doutrina filosófica, religiosa ou moral 'abrangente' (RAWLS, 2003, p.XII). Ou seja, a sua teoria é válida para os contextos onde vigoram a democracia representativa, amparada por uma constituição que garanta as liberdades individuais e a igualdade formal, o "Estado de Direito".

O resultado é a promoção de uma espécie de coesão social em uma "sociedade bem. ordenada" 22 onde existissem instituições políticas que organizassem a estrutura social, possibilitando que os indivíduos cooperem entre si e com as instituições em torno dos princípios de justiça instituídos na posição original. "A posição original é um procedimento de seleção: opera a partir de uma família de concepções de justiça conhecidas e existentes em nossa tradição de filosofia política, ou elaboradas a partir delas" (RAWLS, 2003, p.117). Na posição original, "os representantes dos cidadãos, entendidos apenas como pessoas livres e iguais, devem chegar a um acordo sobre os termos equitativos de cooperação social (conforme expresso por princípios de justiça) que devem regular a estrutura básica da sociedade" (RAWLS, 2003, p.113).

\footnotetext{
20 Vale lembrar que o momento em que Rawls publicou a primeira versão do seu tratado de justiça, “Uma Teoria da Justiça”, na década de 1970, o mundo estava dividido pela Guerra Fria (EUA X URSS). Esse evento mostrou, para aquele momento, que os regimes políticos possuíam duas opções: a democracia liberal em uma sociedade capitalista de livre mercado, onde há uma quase naturalização das desigualdades ou um regime socialista supostamente promotor da "igualdade" à custa, muitas vezes, do cerceamento das liberdades individuais.

${ }^{21}$ Os princípios são postos na ordem que segue, sem possibilidade de inversão. Assim, primeiro vem a questão das garantias das liberdades, primeiro princípio; em segundo, a igualdade equitativa de oportunidade, primeira parte do segundo princípio; e por último, o benefício máximo dos menos favorecidos, segunda parte do segundo princípio.

22 "[...] uma sociedade bem-ordenada é uma sociedade efetivamente regulada por alguma forma de concepção pública (política) de justiça, seja ela qual for" (RAwLS, 2003, p. 13).
} 
Porém, os indivíduos não são iguais entre si, o que leva o autor a utilizar um artifício mental, o "véu da ignorância", cuja finalidade é promover a igualdade e a liberdade para que os representantes realizem o acordo original, ou um novo contrato social, pautado nos dois princípios vistos anteriormente. O "véu da ignorância" impediria que os representantes conhecessem a própria situação e a dos seus representados, o que inviabilizaria qualquer espécie de favorecimento. Assim, sob o risco de eles serem as pessoas menos favorecidas, todos consentem que o melhor acordo é aquele que realiza os dois princípios.

Essa breve abordagem da teoria rawlsiana fornece instrumentos importantes para a continuidade do trabalho e a fundamentação da concepção de justiça adotada. Assim, segundo Brian Barry, a contribuição da teoria rawlsiana reside na

"[...] afirmação do liberalismo que isola as suas características fundamentais, fazendo da propriedade privada dos meios de produção, de distribuição e de troca uma questão contingente, em vez de uma parte essencial da doutrina, e apresenta um princípio de distribuição que poderia, se adequadamente interpretado e com certas assunções factuais, ter implicações igualitárias" (BARRY apud Mouffe, 1996, p.61).

Mouffe menciona outra contribuição de Rawls: a sua "tentativa de proporcionar uma alternativa ao pensamento utilitarista" (MoufFE, 1996, p. 61).

Pressupondo que a Constituição Brasileira de 1988 contempla a existência de um quadro de direitos civis e políticos e de uma igualdade formal perante as leis existentes, e que é função das instituições preservá-los, resta averiguar, no âmbito do OP, se a segunda parte da concepção de justiça rawlsiana, a da equidade e do princípio da diferença, encontra espaço para sua concretização na experiência de OP de Biguaçu-SC. Foi visto que, em três delas, a de Porto Alegre, Belo Horizonte e São Paulo ocorreram em graus diferentes.

Considerando tudo o que foi visto até o momento, as hipóteses testadas se formulam assim:

$\mathrm{H}_{1}$ : O OP do município de Biguaçu promoveu a justiça no que diz respeito à equidade e ao princípio da diferença rawlsiano.

Seja qual for o resultado do teste da $\mathrm{H}_{1}$, validação ou refutação, a segunda hipótese se formula da seguinte forma:

$\mathrm{H}_{2}$ : O desenho institucional da experiência de OP foi decisivo para o alcance dos resultados políticos.

\section{Desenho institucional e justiça no OP de Biguaçu}

Antes de passar às análises que testarão as Hipóteses 1 e 2, faz-se necessária uma breve explicação dos gráficos utilizados. A matriz distributiva adotada reúne em uma representação gráfica bidimensional duas variáveis: IVS (eixo y) e o investimento per capita (eixo x). A distribuição perfeita, com base no referencial teórico, seria aquela onde as regiões do OP mais se aproximam de uma reta ascendente, partindo da extremidade zero, na junção dos dois eixos, e indo até à outra extremidade, 
SILVA, R. Desenho institucional e promoção da justiça em espaços participativos:...

formando uma hipotenusa. A partir dos critérios adotados para estabelecer o corte em cada eixo ${ }^{23}$, formaram-se quatro quadrantes: os das iniquidades distributivas 1 e 2 e os das equidades distributivas 1 e 2. A formação desses quadrantes facilita a leitura dos gráficos sem precisar se deter nos valores em cada eixo.

As análises começam pelo primeiro momento do OP (2002-2005) ${ }^{24}$. Como pode ser observado no Gráfico 1, o OP possibilitou uma reconfiguração do padrão de investimentos públicos, dando prioridade às regiões historicamente negligenciadas pelo poder público. As regiões inseridas nas duas formas representam a antítese justiça/injustiça, sendo que a linha de cor branca representa a promoção da justiça distributiva e, contrariamente, a linha de cor preta representa a promoção da injustiça distributiva. Ou seja, resgatando o referencial de justiça adotado: o OP, no período de 2002 a 2005, promoveu a realização da justiça ao concretizar a equidade e o princípio da diferença. Dessa forma, as desigualdades existentes foram no sentido de favorecer as regiões menos favorecidas com montante maior de investimento per capita, tratando-as de forma diferente das mais bem providas.

\section{Gráfico 1}

Matriz distributiva, $1^{\circ}$ Momento (2002-2005)

investimento per capita dos recursos do OP por região

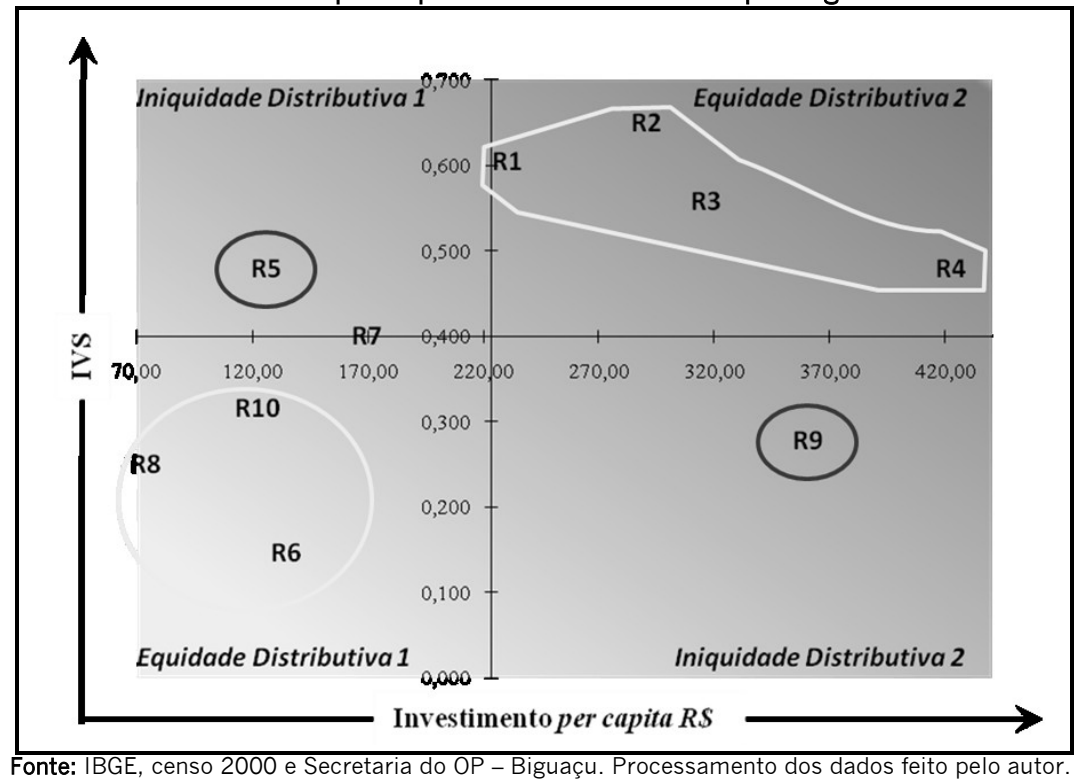

23 Os critérios para estabelecer os pontos de corte em cada eixo foram os seguintes: eixo x (investimento), média dos investimentos no referido período, eixo y (IVS), valor do IVS 0.400 que separa a baixa vulnerabilidade e a categoria não vulnerável (valores abaixo) da relativa, alta e extrema vulnerabilidade (valores acima). Esse critério vale para todos os gráficos que seguirão. 24 Para este primeiro momento, $46 \%$ de todos os recursos decididos no interior do OP foram destinados à pavimentação e à drenagem de ruas. Vale lembrar que a demanda por esse tipo de obra pode ter por trás uma dimensão simbólica de pertencimento ao núcleo urbanizado e central da cidade, evidenciando mais do que uma questão de acesso, mas também de estar incluído ao sistema nervoso central do município. Já o caso da região 9 pode ser explicado pelo fato de a mesma ter sido a destinatária de um montante de recurso ao longo desse período destinado à construção/reforma de um posto de saúde e de uma escola, algo decidido em conjunto pela região e aprovado pelo COP, contando com a solidariedade das outras regiões que abriram mão de parte de seus recursos. 
Contrariamente ao primeiro momento, no segundo, o OP teve seu potencial redistributivo reduzido, obtendo como resultado maior promoção de iniquidade ou injustiça. Analisando a matriz do $2^{\circ}$ momento ${ }^{25}$, Gráfico 2, as regiões 10,13 e 11, nessa ordem, foram as que receberam maior montante de investimento, porém, possuem baixo IVS. Dentre o grupo das regiões mais vulneráveis, apenas a metade recebeu investimentos acima da média no referido período, enquanto o restante esteve abaixo da média para o período ${ }^{26}$. Dessa forma, conclui-se que no segundo momento, após as mudanças institucionais das regras do jogo, o OP não obteve o mesmo desempenho redistributivo do momento anterior, aumentando a promoção de injustiça e diminuindo a promoção da justiça.

\section{Gráfico 2}

Matriz distributiva, $2^{\circ}$ Momento (2006-2008)

investimento per capita dos recursos do OP por região

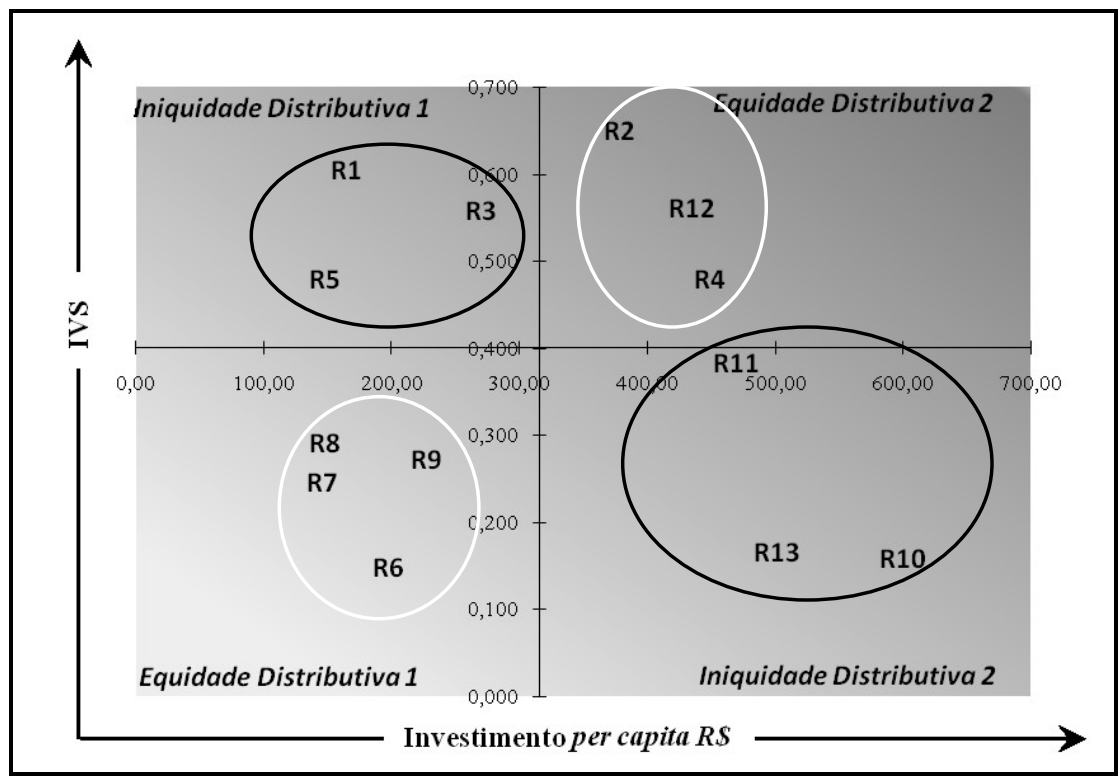

Fonte: IBGE, censo 2000 e Secretaria do OP - Biguaçu. Processamento dos dados feito pelo autor.

Resgatando a primeira hipótese, o que se pode afirmar, com base no resultado da análise, é que ela foi validada parcialmente, ou seja, em partes, o OP de Biguaçu promoveu a justiça. No primeiro momento, houve, em termos gerais, um favorecimento das regiões menos providas de bens e serviços públicos, promovendo a equidade e o princípio da diferença. Assim, as desigualdades na destinação de

\footnotetext{
25 Para este período, $48 \%$ dos recursos decididos no interior do OP foram destinados à pavimentação. Já as regiões 10,11 e 13 foram destinatárias de um montante grande de recursos para construção/reforma de postos de saúde e escolas de educação infantil.

26 Tendo em vista que Biguaçu teve um crescimento populacional vertiginoso nas duas últimas décadas, uma possível explicação para que algumas regiões tenham sido destinatárias de montantes de recursos inferiores aos observados em outras regiões, residiria na capacidade mobilizadora existente em cada região. Logo, regiões cuja população é formada por uma parcela grande de indivíduos oriundos de outros municípios teriam dificuldades para se mobilizarem já que haveria a ausência de vínculo orgânico desses com o local de residência. Porém, observa-se o contrário: as regiões 10, 11 e 13 , que receberam maiores recursos no período 2006-2008, figuram entre as seis regiões com maior percentual de participantes das assembleias regionais oriundos de outros municípios ( $86 \%, 80 \%$ e $79 \%$ respectivamente).
} 
SILVA, R. Desenho institucional e promoção da justiça em espaços participativos:...

recursos entre as regiões ao longo do processo só foram justificáveis devido ao favorecimento das regiões menos favorecidas com mais recursos. Algo que não foi observado, ou foi observado de forma muito residual, no segundo momento da experiência.

Os distintos resultados distributivos produzidos pelos dois momentos do OP conduzem ao questionamento sobre o que levou a obtê-los. É nesse ponto que entra em questão a segunda hipótese " $\mathrm{H}_{2}$ : O desenho institucional da experiência de OP foi decisivo para o alcance dos resultados políticos". Para testá-la, voltar-se-á para o desenvolvimento da experiência ao longo do período estudado, conjuntamente com os dados, confrontando-os com a teoria e os diversos estudos sobre OP.

Tendo em vista que o elemento diferenciador dos dois momentos é a mudança no desenho institucional sofrida pela experiência, ou seja, a mudança "nas regras do jogo", uma das possíveis explicações reside na dimensão institucional. Assim, as regras que dão vida e forma a uma experiência participativa adquirem centralidade na obtenção de resultados políticos, sejam positivos ou negativos. É essa dimensão que produziu resultados distintos no OP do município de Biguaçu nos dois momentos estudados.

Basicamente, o argumento sobre a importância do desenho institucional gira em torno da seguinte afirmação: "as 'instituições importam' decisivamente na produção dos resultados políticos" (PERES, 2008, p. 54). Pelo fato de o OP ser uma instância decisória, cuja forma de participação e de tomada de decisão é regulamentada por um estatuto, "as regras que estruturam o processo decisório seriam as responsáveis não apenas pela estabilidade das decisões como também pelo próprio resultado da escolha" (PERES, 2008, p. 63).

Assim, o núcleo de uma análise que advoga a centralidade das instituições no processo de produção de resultados, segundo Peres, seria

\footnotetext{
“[...] a de que os atores respondem estratégica ou moralmente a um conjunto de regras formais ou informais que são circunscritas às instituições. Estas, moldam, condicionam ou induzem os atores a agirem e a decidirem de determinada maneira e acabam, assim, explicando grande parte do que ocorre na dinâmica da política" (PERES, 2008, p. 65).
}

Conforme visto sucintamente na introdução, ao analisar O OP de Porto Alegre, Lüchmann (2002) apontou três elementos que, conjugados, garantem não só a implementação do OP, como a sua sustentação virtuosa ao longo do tempo ${ }^{27}$. São eles: I- comprometimento político-governamental, II. tradição associativa e III- o desenho institucional. Como bem observou a autora, o desenho institucional é uma dimensão importante para a virtuosidade da experiência que, na capital gaúcha, promoveu a justiça, e no caso de Biguaçu, foi responsável por produzir resultados diferentes.

Apesar das regras do jogo serem responsáveis pelos resultados, no caso do OP de Biguaçu conclui-se que uma leitura que advoga a importância das instituições não pode estar desassociada da dimensão cultural da política local, tendo em vista que a tradição associativa é apontada como um fator importante para o sucesso das experiências de OPs. Caminhando na direção de Avritzer,

\footnotetext{
27 Tese que será defendida na sequência por Avritzer (2003).
} 
“[...] o sucesso dos processos participativos está relacionado não ao desenho institucional e sim à maneira como se articulam desenho institucional, organização da sociedade civil e vontade política de implementar desenhos participativos" (AVRITZER, 2008, p. 47).

Ao resgatar o processo de construção da experiência, observa-se uma complexa relação entre estes fatores: desenho institucional, tradição associativa e comprometimento governamental. A primeira equipe executiva do OP era formada por duas pessoas do PT e uma do PMDB. Foi essa equipe que formulou o desenho institucional ${ }^{28}$ da experiência, tendo como base outras experiências petistas de sucesso: Chapecó e Porto Alegre. Assim, a coordenadora da equipe ligada ao PT procurou, junto com os demais, construir um desenho que expressasse um pouco desse "jeito petista" de governar. Porém, por mais refinado que tenha sido o desenho proposto, não teve respaldo por parte da administração, no caso - PMDB, e por parte dos participantes que não compreenderam toda a engenharia institucional e a sua finalidade. Devido à fraca tradição associativa, que legou apenas à administração municipal a formulação da experiência, faltou à população e às lideranças locais engajamento na discussão da proposta e, com isso, maior assimilação e compreensão da complexidade do desenho do OP, assembleias comunitárias e regionais, um conjunto de pesos no momento de discussão e definição das preferências de investimentos que se traduziam em uma nota que posteriormente se revertia em um percentual de investimento, além de haver as plenárias temáticas.

Dessa forma, a adesão a essa engenharia institucional sofreu restrições que se agravaram com o rompimento do PT. Sob o pretexto de facilitar a compreensão da população acerca das regras do OP, a nova coordenação simplificou o processo, eliminando várias instâncias participativas, excluindo os pesos na definição dos recursos e abrindo espaço para os secretários inserirem suas demandas. Como resultado alegado, o percentual de participação aumentou, assim como os investimentos e o comprometimento governamental. Porém, em termos de desempenho distributivo, o que se observou foi a perda da capacidade do OP em levar bens e serviços públicos às regiões mais vulneráveis. Assim, a primeira equipe, por mais que tenha desenvolvido ações voltadas para a finalidade de maximizar resultados positivos, conforme fora observado em outras experiências, esbarrou no caldo cultural participativo local, que se traduz principalmente na incipiente história associativa do município e que pouco participou do processo de elaboração e implantação do OP, além das resistências da administração, no caso, o PMDB, partido do prefeito ${ }^{29}$.

Por fim, os distintos desempenhos obtidos pela experiência juntamente com o debate institucional remetem à outra discussão que emerge quando a temática participação e maior eficiência na execução de investimentos públicos está em pauta. Pires (2009), ao estudar a experiência de OP de Belo Horizonte ${ }^{30}$, se deparou com um dilema: como conciliar participação (construção autônoma da agenda de investimento por parte da população) com a inserção de um número crescente de regras e critérios técnicos na metodologia do OP que tornam a gestão mais eficiente, porém, sem que haja um

28 O desenho institucional envolve desde a divisão das regiões, escolha dos delegados e conselheiros, participação das associações e da população, as instâncias de participação e o conjunto de regras para a distribuição dos recursos.

29 Conjectura-se que há um cálculo político muito forte, levando a administração a querer possuir maior controle sobre a experiência, porém, tal fato, não nega os avanços conquistados.

30 A experiência de Belo Horizonte possui uma característica peculiar: uma constante preocupação por parte da administração pública em inserir aperfeiçoamentos técnicos que possam conduzir a uma maior eficiência nos gastos do OP. Assim, no interior dos espaços decisórios, existe um conjunto de regras e critérios que governam a interação e a decisão dos participantes, produzindo determinados resultados. 
SILVA, R. Desenho institucional e promoção da justiça em espaços participativos:...

recrudescimento do poder de agenda e autonomia decisória da população participante na definição das obras e serviços a serem priorizados. Para não ir além dos limites estabelecidos nos objetivos, esse aparente dilema não poderá ser trabalhado, porém, como o próprio autor levantou em seu texto, fica a necessidade de se "teorizar e analisar a democracia participativa e seus potenciais impactos sobre as políticas públicas" (PIRES, 2009, p.13).

\section{Conclusão}

Quando se estudam as obras de nomes como Pateman e Macpherson, do modelo de democracia participativa, indiretamente se constata uma importância atribuída ao formato institucional da experiência, seja a participação no ambiente fabril ou no modelo piramidal de participação. Analisando outras experiências participativas como os OPs, inclusive o de Biguaçu, destaca-se o papel central das "regras do jogo" na produção de resultados políticos, mesmo que, em termos da experiência, essa dimensão esteja relacionada às outras duas mapeadas pela literatura especializada.

Conforme visto no artigo, a dimensão do desenho institucional se mostrou vital para a experiência participativa em estudo. Assim, para efeitos de redistribuição de bens e serviços, o desenho institucional interferiu, seja positiva, em um primeiro momento, ou negativamente, após a reformulação das regras do jogo ocorrida posteriormente, e como resultado, ao rompimento do PT. Dessa forma, estudos que visem aprofundar esse debate são essenciais não apenas à participação como também à política entendida em sentido amplo.

Evidenciar a importância da dimensão institucional não é sinônimo de elevá-la ao status de variável explicativa por excelência e única, mas sim, apresentar uma dimensão que, para o escopo do artigo, possuiu um fecundo caráter explicativo. Nesse caso, as mudanças das regras impactaram negativamente no potencial distributivo do OP de Biguaçu.

Uma questão fundamental que emerge desse debate é referente ao volume de recursos destinados às instâncias decisórias do OP. Um maior volume de recurso destinado pela prefeitura ao OP não necessariamente se traduz automaticamente em justiça enquanto equidade. Os resultados obtidos são suficientes para afirmar que mais recursos para o OP de Biguaçu não foi sinônimo de mais justiça, e não seria, considerando a conjuntura, estando condicionada às outras variáveis, como o desenho institucional amplamente abordado.

Este artigo contribui para o campo metodológico, principalmente em como dispor de dados, sem que seja necessário coletá-los em campos, e em como operar massa de dados visando atingir certos objetivos. Nesse caso, o desenvolvimento do Índice de Vulnerabilidade Social (IVS) a partir de dados públicos disponíveis na internet, site do IBGE, foi fundamental para o trabalho, podendo inspirar outros estudos que investiguem não apenas a efetividade das instituições participativas, mas também que procurem a avaliação de certas políticas públicas.

Menciona-se também o aporte teórico utilizado e desenvolvido para fundamentar a concepção de justiça adotada, extraída da filosofia política de Rawls. Ele deu sustentação sólida à concepção de justiça, fornecendo instrumentos que resultaram não apenas na sua definição conceitual, como na construção da primeira hipótese de pesquisa, posteriormente testada. Portanto, ao falar que o OP promove a justiça, não se faz referência a uma noção de justiça surgida a esmo, pelo contrário, tem-se um lastro teórico consistente, mesmo que a apropriação de teoria normativa para fins práticos de 


\section{OPINIÃO PÚBLICA, Campinas, vol. 20, no 2, agosto, 2014, p. 252-272}

política possa trazer desafios e implicar em algumas simplificações, mas são riscos intrínsecos ao processo.

Vale frisar que os limites que assombram os pesquisadores que se propõem a avaliar os resultados de uma experiência participativa, seja qual for o aspecto em voga, são sempre presentes. Nos últimos anos o IPEA (Instituto de Pesquisa Econômica e Aplicada) tem se dedicado a avaliar as diversas experiências participativas no Brasil e, para isso, tem desenvolvido metodologias que cumpram com tal finalidade. Como resultado, foi publicado um volume $\left(n^{\circ} 7\right)$ da série Diálogos para o Desenvolvimento intitulado "Efetividade das Instituições Participativas no Brasil: estratégias de avaliação". Em linhas gerais, consegue-se avançar muito nas estratégias de avaliação, porém, os limites estão sempre incomodando os estudiosos. Adrián Lavalle ilustra bem essa dificuldade em seu texto que compõe o volume:

\footnotetext{
"A multidimensionalidade ou polissemia dos sentidos práticos, teóricos e institucionais torna a participação um conceito fugidio, e as tentativas de definir seus efeitos, escorregadias. Não apenas em decorrência de que a aferição de efeitos é operação sabidamente complexa, mas devido ao fato de sequer existirem consensos quanto aos efeitos esperados da participação, ou, pior, quanto à relevância de avaliá-la por seus efeitos" (LAVALLE, 2011, p. 34).
}

No aspecto metodológico, Vaz e Pires (2011) fazem um endosso às dificuldades inerentes ao processo de avaliação: "Metodologicamente, a tarefa de avaliação na área de ciências sociais é tarefa árdua do ponto de vista do controle de variáveis, efeitos e obtenção de resultados consistentes" (VAZ; PIRES, 2011, p.257). No tocante a este artigo, outras duas limitações devem ser apresentadas. Primeiramente, pressupôs-se um modelo de alocação de bens e serviços públicos, dito "injusto" e construído historicamente, porém, não se verificou empiricamente para o caso da experiência observada. Para tal, seria necessário analisar o período anterior ao OP para se ter um parâmetro comparativo. A outra limitação é que os recursos do OP são uma pequena parte de um montante total que é o Orçamento Municipal. Seria necessário comparar a alocação dos recursos do OP com a alocação de outros recursos realizados diretamente pelo poder executivo municipal. Por fim, as dificuldades expostas não invalidam as iniciativas de estudos que vêm com a perspectiva de contribuir com o entendimento sobre os impactos que as instituições participativas produzem.

\section{Referências Bibliográficas}

Andrade, E. T.; Moura, R. R. "Orçamento Participativo - Bibliografia comentada". Cadernos de Ciência Política. Série: Pré-Edições, n 14. Programa de Pós-Graduação em Ciência Política/UFRGS, Porto Alegre, 2000.

ARaujo, C. "Legitimidade, justiça e democracia: o novo contratualismo de Rawls". Lua Nova, n57, p.73.85, 2002.

Avritzer, L. O Orçamento Participativo e a Teoria Democrática: um balanço crítico. In: AvritZer, L.; Navarro, Z. $A$ inovação democrática no Brasil: o Orçamento Participativo. São Paulo: Cortez, 2003.

"Instituições participativas e desenho institucional: algumas considerações sobre a variação da participação no Brasil democrático". Opinião Pública, vol. 14, nº 1, p.43.64, 2008. 


\section{SILVA, R. Desenho institucional e promoção da justiça em espaços participativos:...}

.; PIRES, R. R. "Orçamento Participativo, efeitos distributivos e combate à pobreza". Teoria \& Sociedade, $\mathrm{n}^{\circ}$ especial: Políticas sociais e democracia no Brasil, p.68-89, 2005.

; NavarRo, Z. A inovação democrática no Brasil: o Orçamento Participativo. São Paulo: Cortez, 2003.

Borba, J.; LuChmann, L. Orçamento Participativo: Análise das experiências desenvolvidas em Santa Catarina. Florianópolis: Insular, 2007.

CARLOS, E. Controle Social e Política Redistributiva no Orçamento Participativo. Vitória: Edufes, 2007.

Downs, A. Uma Teoria Econômica da Democracia. São Paulo: Edusp, 1999.

Hall, P.; TAYloR, R. “As três versões do neoinstitucionalismo". Lua Nova, n 58, p.193-223, 2003.

IBGE. Censo Demográfico, 2000.

Censo Demográfico, 2000: agregado por setor censitário dos resultados do universo. Rio de Janeiro, 2003.

KogA, D. Medidas de cidades: entre territórios de vida e territórios vividos. São Paulo: Cortez, 2003.

LAVAlle, A.G. Participação: valor, utilidade, efeitos e causa. In: PIRES, R. Efetividade das instituições participativas no Brasil: estratégias de avaliação. Brasília: IPEA, 2011.

LÜChmann, L. H. H. "Possibilidades e limites da democracia deliberativa: a experiência do Orçamento Participativo em Porto Alegre". Tese de Doutorado - UNICAMP, Campinas, p.223, 2002.

MACPHERSON, C. A Democracia Liberal: origens e evolução. Rio de Janeiro: Zahar Editores, 1978.

MarquettI, A. Participação e Redistribuição: o Orçamento Participativo em Porto Alegre. In: AvRItzer, L.; NAvARRo, Z. (orgs.). A inovação democrática no Brasil. São Paulo: Cortez, 2003.

.; CAmpos, G. A.; PIRES, R. (orgs.). Democracia participativa e redistribuição: análise de experiências de orçamento participativo. São Paulo: Xamã, 2008.

MIGuel, L. F. “Teoria Democrática Atual: Esboço de Mapeamento”. B/B - Boletim Informativo Bibliográfico, 59, São Paulo, p. 5.42, 2005.

Mouffe, C. O regresso do político. Lisboa: Gradiva, 1996.

NAhAS, M. I. P.; OliveiRA, A. M.; Neto, A. C. Acesso à ocupação e a renda versus escolarização no espaço intraurbano de grandes cidades: o caso de Belo Horizonte. Seminário sobre a Economia Mineira, 2002, Belo Horizonte. Anais Eletrônicos. Belo Horizonte: UFMG, 2002. Disponível em:

<http://www.cedeplar.ufmg.br/diamantina2002/textos/D73.PDF>. Acesso em: 27 jun.2012.

Nobre, A. Inovações institucionais em Santa Catarina: o caso do Orçamento Participativo de Biguaçu - 2001/2004. In: BorBA, J; LüCHMANN, L. (orgs.). Orçamento Participativo: Análise das experiências desenvolvidas em Santa Catarina. Florianópolis: Insular, 2007.

Orçamento Participativo. Plano de Investimento (2002-2008).

Pateman, C. Participação e Teoria Democrática. Rio de Janeiro: Paz e Terra, 1992.

PIRES, R. "Participação Cidadã e Planejamento Governamental: um equilíbrio possível? Reflexões sobre o Orçamento Participativo de Belo Horizonte". Pensar BH/Política Social. Belo Horizonte, n²4, p.10-13, nov. 2009.

PERES, P. S. "Comportamento ou instituições? A evolução histórica do neoinstitucionalismo da ciência política". Revista Brasileira de Ciências Sociais, vol. 23, nº8, p.53.71, 2008.

Prefeitura de Porto Alegre. Mapas e indicadores das vulnerabilidades sociais. [Online] 2007. Disponível em: <www.portoalegre.rs.gov.br>. Acesso em: 27 jul. 2012.

RawLS, J. O liberalismo político. São Paulo: Ática, 2000.

Justiça como equidade: uma reformulação. São Paulo: Martins Fontes, 2003.

SARTORI, G. A teoria da democracia revisitada - o debate contemporâneo. São Paulo: Ática S. A., 1994.

SILVA, R. "Redistribuição e inclusão: o orçamento participativo de Biguaçu e as eleições municipais". Dissertação de Mestrado do Programa de Pós-Graduação em Sociologia Política - UFSC, p.152, Florianópolis, 2010. 
SouZA, J. A construção social da subcidadania: para uma sociologia da modernidade periférica. Belo Horizonte: Editora UFMG; Rio de Janeiro: IUPERJ, 2003a.

“(Não) reconhecimento e subcidadania, ou o que é "ser gente"?" Lua Nova, n 59, 2003b.

. Por uma teoria da ação social da modernidade periférica: um diálogo crítico com Florestan Fernandes. In: SouzA, J. (org.). A invisibilidade da desigualdade brasileira. Belo Horizonte: Editora UFMG, 2006.

VAZ, A.; PIRES, R. Comparações entre municípios: avaliação dos efeitos da participação por meio de pares contrafactuais. In: Pires, R. Efetividade das instituições participativas no Brasil: estratégias de avaliação. Brasília: IPEA, 2011.

Rafael da Silva·rsilva@uem.br

Submetido à publicação em maio de 2013.

Versão final aprovada em abril de 2014. 